\title{
Single Low-Dose Radiation Induced Regulation of Keratinocyte Differentiation in Calcium-Induced HaCaT Cells
}

\author{
Hyung Jin Hahn, Hae Jeong Youn ${ }^{1}$, Hwa Jun $\mathrm{Cha}^{2}$, Karam $\mathrm{Kim}^{2}$, Sungkwan $\mathrm{An}^{2, *}$, Kyu Joong Ahn ${ }^{1, *}$ \\ Department of Dermatology, Uijeongbu St. Mary's Hospital, College of Medicine, The Catholic University of Korea, Uijeongbu, \\ ${ }^{1}$ Department of Dermatology, Konkuk University School of Medicine, ${ }^{2}$ Korea Institute for Skin and Clinical Sciences and \\ Molecular-Targeted Drug Research Center, Konkuk University, Seoul, Korea
}

Background: We are continually exposed to low-dose radiation (LDR) in the range $0.1 \mathrm{~Gy}$ from natural sources, medical devices, nuclear energy plants, and other industrial sources of ionizing radiation. There are three models for the biological mechanism of LDR: the linear no-threshold model, the hormetic model, and the threshold model. Objective: We used keratinocytes as a model system to investigate the molecular genetic effects of LDR on epidermal cell differentiation. Methods: To identify keratinocyte differentiation, we performed western blots using a specific antibody for involucrin, which is a precursor protein of the keratinocyte cornified envelope and a marker for keratinocyte terminal differentiation. We also performed quantitative polymerase chain reaction. We examined whether LDR induces changes in involucrin messenger RNA (mRNA) and protein levels in calcium-induced keratinocyte differentiation. Results: Exposure of HaCaT cells to LDR (0.1 Gy) induced p21 expression. p21 is a key regulator that induces growth arrest and represses stemness, which accelerates keratinocyte differentiation. We correlated involucrin expression with

Received May 21, 2015, Revised September 15, 2015, Accepted for publication September 16, 2015

*These authors equally contributed to this work.

Corresponding author: Kyu Joong Ahn, Department of Dermatology, Konkuk University School of Medicine, 120 Neungdong-ro, Gwangjin-gu, Seoul 05029, Korea. Tel: 82-2-2030-5172, Fax: 82-2-2030-5179, E-mail: kjahn@ kuh.ac.kr

This is an Open Access article distributed under the terms of the Creative Commons Attribution Non-Commercial License (http://creativecommons. org/licenses/by-nc/4.0) which permits unrestricted non-commercial use, distribution, and reproduction in any medium, provided the original work is properly cited.

Copyright (c) The Korean Dermatological Association and The Korean Society for Investigative Dermatology keratinocyte differentiation, and examined the effects of LDR on involucrin levels and keratinocyte development. LDR significantly increased involucrin mRNA and protein levels during calcium-induced keratinocyte differentiation. Conclusion: These studies provide new evidence for the biological role of LDR, and identify the potential to utilize LDR to regulate or induce keratinocyte differentiation. (Ann Dermatol 28(4) 433 437, 2016)

-Keywords-

Cell differentiation, Keratinocytes, Low-dose radiation

\section{INTRODUCTION}

Low-dose radiation (LDR; $\leq 100$ cGy) is used for diagnostic imaging and interventional radiology ${ }^{1}$. We are continuously exposed to LDR from natural sources, medical devices, nuclear energy plants, and other industrial sources of ionizing radiation ${ }^{2}$. Therefore, it is important to understand the biological effects of LDR. The biological effects of LDR have been explained by the linear no-threshold (LNT) model, which considers that LDR effects are similar to those of high-dose ionizing radiation (HDR). The LNT model suggests that, similar as HDR, even very low exposure to LDR can cause harmful DNA lesions, such as single-strand breaks, double-strand breaks, apurinic/apyrimidinic site (either apyrimidinic or apurinic), DNA-DNA and DNA-protein cross-linking, and a plethora of base modifications ${ }^{3}$. However, there is some debate whether LDR is harmful to living organisms. Some studies have shown that LDR induces beneficial effects on DNA stability, growth rate, survival, life span, and immune activa- 
tion, whereas other studies have shown that LDR has no biological effects ${ }^{4-8}$. Repeated exposure to LDR induces adaptation to ionizing radiation. Therefore, understanding the biological effects of LDR is crucial, particularly with the increasing use of LDR in medical and therapeutic protocols.

The epidermis is the outermost layer of the body, which forms a physical and immunological barrier. Keratinocytes are the most abundant cells in the epidermis ${ }^{9}$. Differentiating keratinocytes migrate from the stratum basale to the stratum corneum; this migration is implicated in forming the physical and immunological barrier and helping to form a multilayered epidermis. Mouse skin keratinocytes exposed to HDR exhibit accelerated differentiation due to the activation of protein kinase $C$ (PKC) signaling pathways $^{10}$. HDR-mediated activation of PKC induces the G2/M arrest and reduces keratinocyte stemness, which accelerates the initiation of keratinocyte differentiation ${ }^{11}$. In this study, we investigate whether LDR also accelerates keratinocyte differentiation.

\section{MATERIALS AND METHODS}

\section{Cell culture and exposure to ionizing radiation}

HaCaT cells were obtained from Cell Lines Service (Eppelheim, Germany) and cultured as described in a previous study ${ }^{12}$ in serum-free medium (GIBCO; Invitrogen, Carlsbad, CA, USA). Cells were cultured at $37^{\circ} \mathrm{C}$ in a humidified atmosphere with $5 \% \mathrm{CO}_{2}$. For exposure to ionizing radiation, cells were seeded in a $60 \mathrm{~mm}$ culture dish (SPL Life Sciences, Seoul, Korea) and exposed to a ${ }^{137} \mathrm{Cs}$ $\gamma$-ray source (MDI-KIRAMS 137 irradiator; Korea Institute of Radiological and Medical Sciences, Seoul, Korea).

\section{Cell viability analysis}

Cell viability was determined by the tetrazolium salt (WST-1) assay (EZ-Cytox Cell Viability Assay kit; ITSbio, Seoul, Korea). HaCaT cells $\left(1 \times 10^{4}\right.$ cells $)$ were seeded into the wells of 96-well plates and cultured for $24 \mathrm{~h}$. Then, cells were irradiated with 0, 0.01, 0.05, and 0.1 Gy gamma radiation (MDI-KIRAMS 137) and incubated for $28 \mathrm{~h}$. Next, WST-1 solution was added to LDR-irradiated cells for $30 \mathrm{~min}$. After incubation for $30 \mathrm{~min}$, the absorbance of the samples at $450 \mathrm{~nm}$ was measured spectrophotometrically using a plate reader (iMark plate reader; Bio-Rad Laboratories Inc., Hercules, CA, USA). The optical density of each well was determined to quantify cell viability.

\section{Western blot analysis}

Western blot assays were performed on cell pellet lysates in radioimmunoprecipitation assay buffer with protease in- hibitors (Roche, Basel, Switzerland), as previously described $^{13}$. The antibodies used were anti-involucrin (Santa Cruz Biotechnology, Santa Cruz, CA, USA), and anti- $\beta$ actin (Sigma-Aldrich, St. Louis, MO, USA). Western blots were scanned and band intensities were quantified using Image (National Institutes of Health, Bethesda, MD, USA).

\section{Quantitative polymerase chain reaction}

Quantitative polymerase chain reaction (PCR) was performed as described previously ${ }^{14}$. In brief, total RNA was isolated using TRIzol (Invitrogen; Life Technologies, Grand Island, NY, USA) according to the manufacturer's instructions. Then, cDNAs were synthesized from $1 \mu \mathrm{g}$ total RNA using reverse transcriptase (Bioneer, Daejeon, Korea). PCR was performed using SYBR Green I in a PCR premix and a LineGene $\mathrm{K}$ cycler (BioER, Hangzhou, China). All results shown are representative of at least three independent experiments. All primers used for PCR have been reported in a previous study and include: involucrin forward primer, 5-CAAAGAACCTGGAGCAGG AG-3; involucrin reverse primer, 5-CAGGGCTGGTTGAA TGTCTT3; $\beta$-actin forward primer, 5-CGACAGGATGCA GAAGGAG-3; and $\beta$-actin reverse primer, 5-ACATCTG CTGGAAGGTGGA-3. $\beta$-actin was used as the internal loading control. Changes in relative levels of involucrin messenger RNA (mRNA) were obtained by relating each PCR product to its internal loading control.

\section{Statistical analysis}

Statistical significance was determined by t-test with Microsoft Excel 2016 (Microsoft, Redmond, WA, USA). A $p$-value 0.05 was considered statistically significant.

\section{RESULTS AND DISCUSSION}

\section{LDR accelerates keratinocyte differentiation}

LDR increased involucrin protein levels in calcium-activated developing keratinocytes (Fig. 1). The relative involucrin expression level was elevated from 2,649.03 to $17,053.31$ at day 8. LDR also induced increases in involucrin mRNA levels (Fig. 2). Involucrin is a representative marker of keratinocyte differentiation, and accumulates according to the level of differentiation ${ }^{15}$. Therefore, LDR-induced increases in involucrin mRNA and protein levels indicate that ionizing radiation facilitates calcium-mediated keratinocyte differentiation. In previous studies, gamma radiation has diverse effects on proliferation, DNA repair, release of cytokines and etc. in in vitro cellular as well as in vivo models ${ }^{16-20}$. Especially, high gamma radiation increases calcium-induced keratinocyte 
differentiation through activating PKC signaling pathway in keratinocytes ${ }^{10}$. Thus, in our present study, we show

A

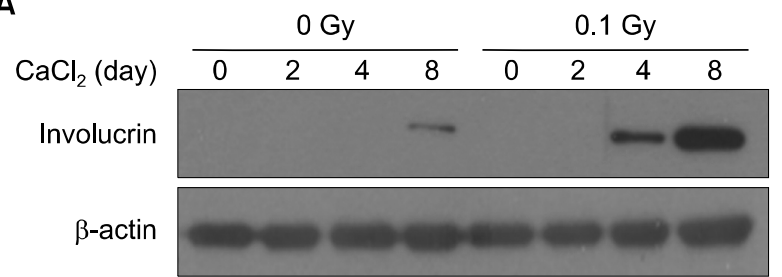

B

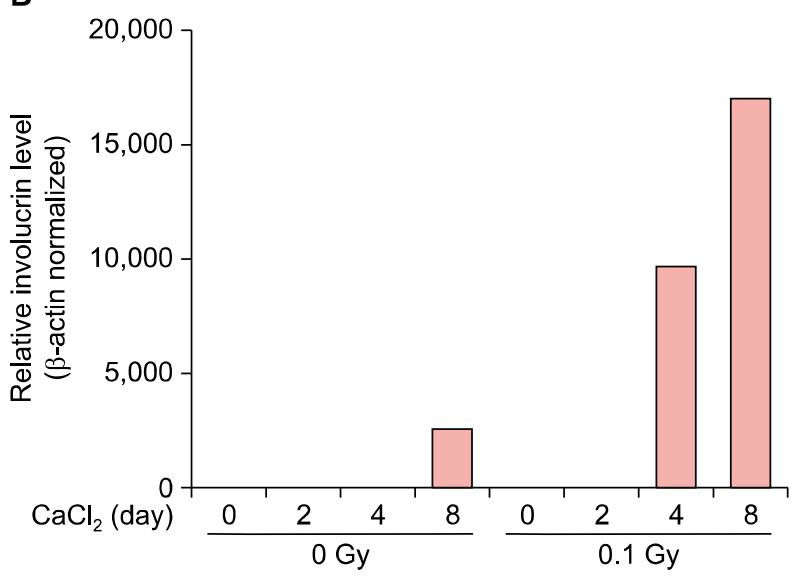

Fig. 1. Low-dose radiation stimulates involucrin accumulation in calcium-induced differentiating keratinocytes. (A) Western blot analysis of involucrin protein levels in control HaCaT cells (no exposure to ionizing radiation) and $\mathrm{HaCaT}$ cells exposed to 0.1 Gy gamma irradiation. In each experiment, equal loading was demonstrated by immunostaining for $\beta$-actin. (B) The band densities of interest were further analyzed by ImageJ. Involucrin levels were normalized against $\beta$-actin.

A

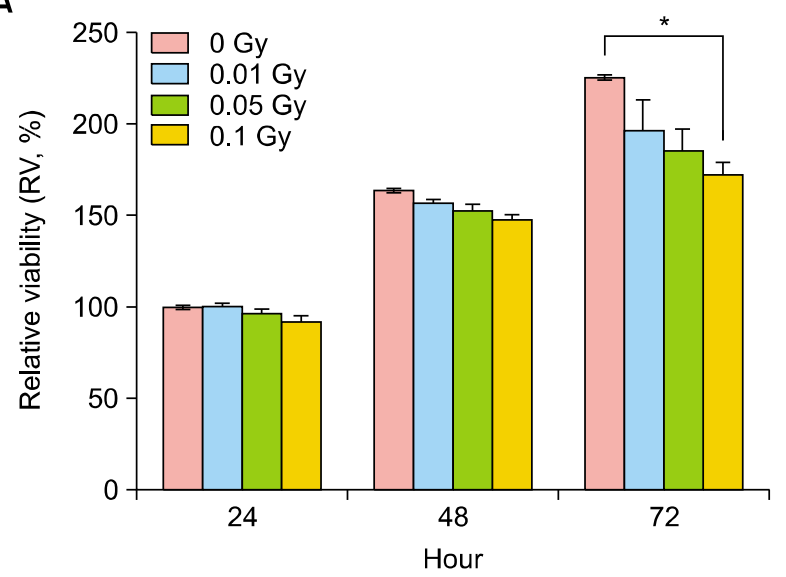

that effects of LDR on keratinocyte differentiation.

\section{LDR induces growth arrest by elevating p21 (Cip1/Waf1) expression}

Song et al. ${ }^{10}$ show that HDR-induced acceleration of calcium-mediated keratinocyte differentiation is caused by a reduction in stemness and growth arrest due to PKC activation. Therefore, we tested whether LDR could in-

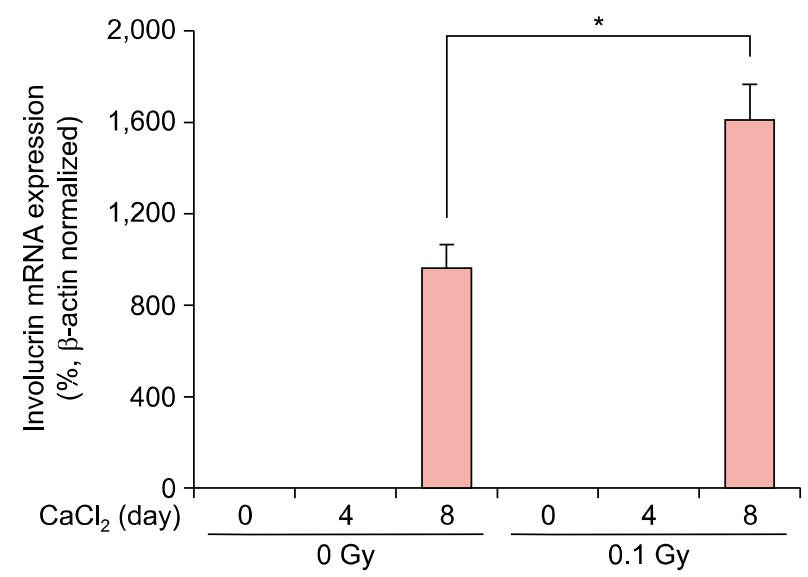

Fig. 2. Low-dose radiation elevates involucrin messenger RNA (mRNA) expression in calcium-induced differentiating keratinocytes. HaCaT cells were exposed to gamma radiation and control cells were untreated. After $4 \mathrm{~h}$, keratinocyte differentiation was induced in HaCaT cells using $2 \mathrm{mM}$ calcium for 4 and 8 days. Total RNA, isolated using TRIzol, was used to synthesize cDNA by reverse transcription, and was amplified by polymerase chain reaction. $\beta$-actin was amplified as a normalization control. Results are expressed as the mean percentage \pm standard error of the experiments performed in triplicate. ${ }^{*} p<0.01$.

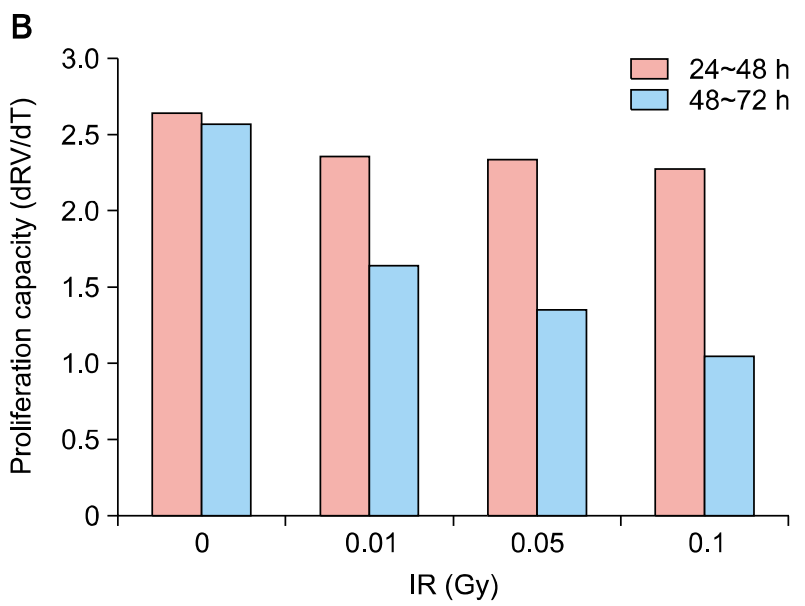

Fig. 3. Low-dose radiation reduced cell viability and growth capacity in HaCaT cells. (A) HaCaT cells $\left(1 \times 10^{4}\right.$ cells $)$ were plated in 96-well plates and cultured for 24, 48, and $72 \mathrm{~h}$ after the exposure to the indicated dose of gamma radiation. Cell viability was measured by WST-1 as described in Materials and Methods. Results are expressed as the mean optical density \pm standard error, as a percentage of the control for the experiments performed in triplicate. ${ }^{*} p<0.01$. (B) Growth capacity was calculated by calculating the $\mathrm{dRV} / \mathrm{dT}$ as derivative relative viability $(\%) /$ derivative time (h). IR: gamma irradiation. 
A

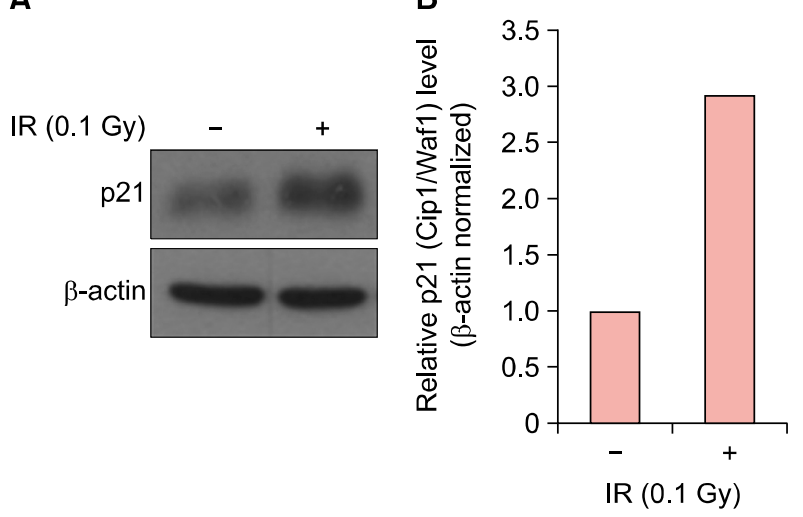

Fig. 4. Low-dose radiation induced p21 (Cip1/Waf1) expression in HaCaT cells. (A) Western blot analysis of p21 (Cip1/Waf1) protein levels in control $\mathrm{HaCaT}$ cells and $\mathrm{HaCaT}$ cells exposed to $0.1 \mathrm{~Gy}$ gamma irradiation. Equal loading in each experiment was demonstrated by immunostaining for $\beta$-actin. (B) Band densities of interest were further analyzed by Imagej; p21 (Cip1/Waf1) levels were normalized against $\beta$-actin. IR: gamma irradiation.

duce keratinocyte growth arrest (Fig. 3). The results showed that LDR reduced keratinocyte viability in a timeand dose-dependent manner (Fig. 3), which is similar to the effects of HDR. Cell proliferation capacity was reduced by the exposure to 0.1 Gy LDR from 2.58 to 1.05 at $48 \sim 72 \mathrm{~h}$, which suggested that LDR induced growth arrest. We also found that LDR elevated p21 (Cip1/Waf1) expression in the HaCaT cells (Fig. 4).

In general, increase of p21 (Cip1/Waf1) suppresses broad range of cyclin/CDK complexes, which leads to G1, G2 and S-phase arrest. Thus, p21 (Cip1/Waf1) represses stemness through the regulation of the cell $\mathrm{cycle}^{21}$, and is a well-characterized radiation marker that is activated by PKC ${ }^{11,22}$. In keratinocytes, p21 (Cip1/Waf1) is increased by calcium-induced keratinocyte differentiation ${ }^{23}$. And overexpression of p21 (Cip1/Waf1) induces acceleration of keratinocyte differentiation ${ }^{23}$. Therefore, since keratinocytes initiates differentiation through halting cell proliferation and decreasing stemness, LDR-mediated elevation of p21 (Cip1/Waf1) facilitated calcium-mediated keratinocyte differentiation.

lonizing radiation activates the PKC signaling pathway, which elevates the p21 expression levels. The PKC signaling pathway activation and elevation of p21 expression levels induces cell growth arrest and reduces stemness, which accelerates keratinocyte differentiation in $\mathrm{HaCaT}$ cells exposed to LDR. These results are consistent with previous results showing that HDR accelerates keratinocyte differentiation. Our results provide new evidence for the biological role of LDR, and suggest the potential uti- lization of LDR as an inducer of keratinocyte differentiation on in vitro model.

\section{ACKNOWLEDGMENT}

This study was supported by grants from the Ministry of Trade, Industry and Energy (grant no. 20131610101840) and the Ministry of Science, ICT and Future Planning (grant no. 20110028646) of the Republic of Korea.

\section{REFERENCES}

1. Mobbs SF, Muirhead CR, Harrison JD. Risks from ionising radiation: an HPA viewpoint paper for Safegrounds. J Radiol Prot 2011;31:289-307.

2. Bae S, Kim K, Cha HJ, Choi Y, Shin SH, An IS, et al. Low-dose $\gamma$-irradiation induces dual radio-adaptive responses depending on the post-irradiation time by altering microRNA expression profiles in normal human dermal fibroblasts. Int J Mol Med 2015;35:227-237.

3. Bae S, Kim K, Cha HJ, Choi Y, Shin SH, An IS, et al. Altered microRNA expression profiles are involved in resistance to low-dose ionizing radiation in the absence of BMI1 in human dermal fibroblasts. Int J Oncol 2014;45:1618-1628.

4. Liang X, So YH, Cui J, Ma K, Xu X, Zhao Y, et al. The low-dose ionizing radiation stimulates cell proliferation via activation of the MAPK/ERK pathway in rat cultured mesenchymal stem cells. J Radiat Res 2011;52:380-386.

5. Ahmed KM, Nantajit D, Fan M, Murley JS, Grdina DJ, Li JJ. Coactivation of ATM/ERK/NF-kappaB in the low-dose radiation-induced radioadaptive response in human skin keratinocytes. Free Radic Biol Med 2009;46:1543-1550.

6. Moskalev AA, Plyusnina EN, Shaposhnikov MV. Radiation hormesis and radioadaptive response in Drosophila melanogaster flies with different genetic backgrounds: the role of cellular stress-resistance mechanisms. Biogerontology 2011; 12:253-263.

7. Seong KM, Kim CS, Seo SW, Jeon HY, Lee BS, Nam SY, et al. Genome-wide analysis of low-dose irradiated male Drosophila melanogaster with extended longevity. Biogerontology 2011;12:93-107.

8. Ina $Y$, Sakai K. Activation of immunological network by chronic low-dose-rate irradiation in wild-type mouse strains: analysis of immune cell populations and surface molecules. Int J Radiat Biol 2005;81:721-729.

9. Eckert RL, Rorke EA. Molecular biology of keratinocyte differentiation. Environ Health Perspect 1989;80:109-116.

10. Song HJ, Cho CK, Yoo SY, Park KS, Lee YS. Increased induction of $\mathrm{Ca}^{2+}$-mediated differentiation by gamma ray is mediated by endogenous activation of the protein kinase $\mathrm{C}$ signaling pathways in mouse epidermal cells. Int J Radiat Oncol Biol Phys 1998;41:897-904.

11. Barboule N, Lafon $C$, Chadebech $P$, Vidal S, Valette A. Involvement of p21 in the PKC-induced regulation of the G2/M cell cycle transition. FEBS Lett 1999;444:32-37.

12. Cha HJ, Lee OK, Kim SY, Ko JM, Kim SY, Son JH, et al. 
MicroRNA expression profiling of p-phenylenediamine treatment in human keratinocyte cell line. Mol Cell Toxicol 2015;11:19-28.

13. Cha HJ, Bae S, Kim K, Kwon SB, An IS, Ahn KJ, et al. Overdosage of methylparaben induces cellular senescence in vitro and in vivo. J Invest Dermatol 2015;135:609-612.

14. Kwon KJ, Bae S, Kim K, An IS, Ahn KJ, An S, et al. Asiaticoside, a component of Centella asiatica, inhibits melanogenesis in B16F10 mouse melanoma. Mol Med Rep 2014;10:503-507.

15. Watt FM. Involucrin and other markers of keratinocyte terminal differentiation. J Invest Dermatol 1983;81(1 Suppl): 100s-103s.

16. Tsukimoto $M$, Homma $T$, Ohshima $Y$, Kojima $S$. Involvement of purinergic signaling in cellular response to gamma radiation. Radiat Res 2010;173:298-309.

17. Sudprasert W, Navasumrit $P$, Ruchirawat M. Effects of low-dose gamma radiation on DNA damage, chromosomal aberration and expression of repair genes in human blood cells. Int J Hyg Environ Health 2006;209:503-511.

18. Han SK, Song JY, Yun YS, Yi SY. Effect of gamma radiation on cytokine expression and cytokine-receptor mediated
STAT activation. Int J Radiat Biol 2006;82:686-697.

19. Pourfathollah AA, Shaiegan M, Namiri M, Babae GR. Effect of gamma irradiation on lymphocyte proliferation and IL-8 production by lymphocytes isolated from platelet concentrates. Arch Med Res 2008;39:590-593.

20. Zhang Z, Zhang H, Liu F, Qiu M, Tong J. Effects of gamma radiation on bone-marrow stromal cells. J Toxicol Environ Health A 2010;73:514-519.

21. Yew TL, Chiu FY, Tsai CC, Chen HL, Lee WP, Chen YJ, et al. Knockdown of p21(Cip1/Waf1) enhances proliferation, the expression of stemness markers, and osteogenic potential in human mesenchymal stem cells. Aging Cell 2011;10: 349-361.

22. Bluwstein A, Kumar N, Léger K, Traenkle J, Oostrum Jv, Rehrauer $\mathrm{H}$, et al. PKC signaling prevents irradiationinduced apoptosis of primary human fibroblasts. Cell Death Dis 2013;4:e498.

23. Todd C, Reynolds NJ. Up-regulation of p21WAF1 by phorbol ester and calcium in human keratinocytes through a protein kinase C-dependent pathway. Am J Pathol 1998; 153:39-45. 